\title{
Influence of Loading Peak and Loading Rate on Twin Fibers Pullout Test of Concrete Matrix
}

\author{
Zhang Yafang ${ }^{1, *}$,Luo Feihua ${ }^{1}$, Lu Juan ${ }^{1}$, He Juan ${ }^{1}$, Zhuang Yuhai ${ }^{2}$ \\ ${ }^{1}$ School of Civil Engineering, Guangzhou University, Guangzhou 510006, China; \\ ${ }^{2}$ Guangzhou City Construction \& Development Co. Ltd. 510085, P. R. China
}

\begin{abstract}
Numerical analysis software based on linear finnite element method and statistical damage theory concrete material has been adopted in this study. Dynamic numerical model of twin fibers pullout test of concrete matrix have been created by considering the meso-heterogeneity of concrete material. The whole process from micro-cracks initiation, propagation to crack penetration has been simulated. The influence of stress wave loading peak and loading rate on twin fibers pull-out test of concrete matrix under dynamic load has, therefore, been scrutinized. Results show that loading rate has effect on failure mode and crack propagation along interface of the twin fibers pull-out specimens. With increasing loading rates, the rate of interface crack propagation and damage area increase either.
\end{abstract}

\section{Introduction}

Fiber reinforced concrete is widely used in civil and structural engineering. Due to the physical and chemical interactions between the fibers and the matrix, a nanoscale thin layer is formed during the processing of the composites, which is called the interface ${ }^{[1]}$. The interface between fiber and matrix in fiber reinforced concrete is an important microstructure. The efficiency of stress transfer between interfaces plays an important role in the overall properties of composites under different loading conditions $^{[2-3]}$. There is a significant difference between the mechanical properties of concrete materials under dynamic load and quasi-static action ${ }^{[4]}$. At present, some scholar ${ }^{[5-8]}$ consider the drawing performance experiments of deformed steel fibers with loading rate.in addition, because the bond mechanism between steel fiber and concrete is equivalent to that between steel bar and concrete[9], some scholars have analyzed the mechanism of steel fiber and concrete by studying the bond properties of steel bar and concrete at different loading rates [10${ }^{11}$.Aiming at the complexity of the double-wire dynamic pull-out problem, this study, considering the influence of the fiber interface properties, establishes the dynamic numerical model of the double-wire pull-out of concrete by using RFPA2D-Dynamic (Realistic Failure Process Analysis) numerical analysis software, and probes into it the influence of loading peak and loading rate on the pullout performance of concrete double wire is discussed.

\section{Numerical model}

Most of the existing studies use macroscopic elastoplastic theory to describe the nonlinear behavior of concrete load damage and cracking process based on the uniformity of materials, ignoring the mesoscopic non-uniformity of concrete phase materials, it is difficult to accurately express the entire failure process of concrete complexity [12]. The calculation method of the RFPA ${ }^{2 \mathrm{D}}$-Dynamic system is mainly based on linear finite element theory and statistical damage theory. The Weibull distribution function is adopted to consider the non-uniformity of the mechanical properties of the mesoscopic elements of concrete materials. The Weibull statistical distribution function expression is:

$$
f(x)=\frac{m}{x_{0}}\left(\frac{x}{x_{0}}\right)^{m-1} \exp \left(-\frac{x}{x_{0}}\right)^{m}
$$

In the formula: $m$ is the homogeneity of the material, the greater the homogeneity, the more uniform the material; $x_{0}$ represents the average value of the mechanical properties of mesoscopic units of each phase material.The dynamic numerical model of twin fibers shown in Fig 1. The steel fibers in the model were defined as No. 1 and No. 2 respectively. The geometric parameters of the numerical model were as follows: the matrix size was $40 \mathrm{~mm} \times 40 \mathrm{~mm}$, which was divided into 102400 units ( 320 $\times 320$ ) , the diameter of the steel fiber was $0.5 \mathrm{~mm}$, the distance between the twin fibers was $10 \mathrm{~mm}$, the embedding depth was $20 \mathrm{~mm}$, and the interface size was $0.125 \mathrm{~mm} \times 20 \mathrm{~mm}$. The mechanical parameters and homogeneity of the materials in each phase in the numerical model shown in table 1 , and the values were referenced [12-13]. 


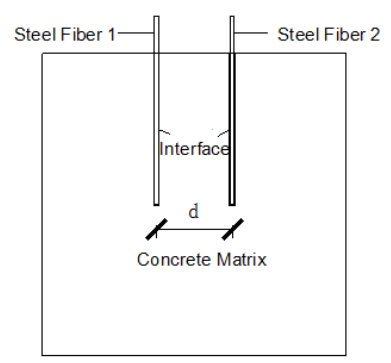

Fig1. Numerical simulation model

Table1. Mechanical parameters of numerical model

\begin{tabular}{cccl}
\hline Component & $\begin{array}{c}\text { Elastic } \\
\text { Modulus/MPa }\end{array}$ & $\begin{array}{c}\text { Ultimate tensile } \\
\text { strength/MPa }\end{array}$ & Poisson ratio \\
\hline Cement mortar & $20400(3)$ & $3.2(3)$ & $0.25(100)$ \\
Interface & $3500(1.5)$ & $0.5(1.5)$ & $0.25(100)$ \\
Steel fiber & $210000(15)$ & $1000(15)$ & $0.30(100)$ \\
\hline
\end{tabular}

Note: The values in parentheses represented the homogeneity of the material.

In order to explore the influence of the peak load and the change of the load rate on the performance of the twin fibers pullout of concrete matrix, a triangular dynamic stress wave as shown in Fig 2 was applied to the steel fiber in the model, with a total loading time of $20 \mu \mathrm{s}$. In the numerical calculation, the propagation distance of the internal wave in each time step should be smaller than the unit size. In this study, the time step was $0.1 \mu \mathrm{s}$, and the total number of loading steps was 200 steps.

As shown in Fig 2, in order to study the effect of loading peaks, the stress wave rise time was fixed at $5 \mu \mathrm{s}$, and the loading peaks were taken to be $30 \mathrm{MPa}, 35 \mathrm{MPa}$, $40 \mathrm{MPa}, 45 \mathrm{MPa}, 50 \mathrm{MPa}, 55 \mathrm{Mpa}$, for future discussion, followed by the numbers Peak 1, Peak 2, Peak 3, Peak 4, Peak 5, Peak 6. In order to study the effect of loading rate, the peak load was fixed at $50 \mathrm{MPa}$, and the rise time was taken to be $2 \mu \mathrm{s}, 6 \mu \mathrm{s}, 10 \mu \mathrm{s}, 14 \mu \mathrm{s}$, and $18 \mu \mathrm{s}$. The effect of loading rate was considered by changing the lifting time. The larger, the number was Rate 1, Rate 2, Rate 3, Rate 4, Rate 5.

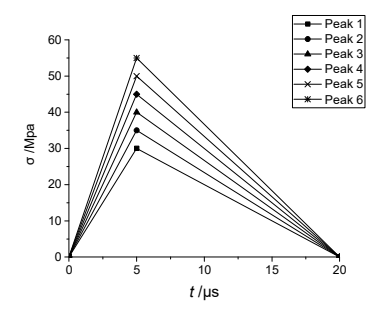

(a) Loading peak curve

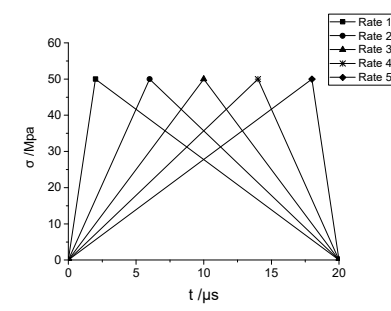

(b) Loading rate curve
Fig2. Dynamic loading curve

\section{Results discussion}

\subsection{Dynamic failure mode}

Peak 2, Peak 4, Peak 6, and Rate 1, Rate 2, and Rate 5 specimens are shown in Fig 3 at the time of loading time $\mathrm{t}$ $=10 \mu \mathrm{s}$ and $20 \mu \mathrm{s}$, respectively. The stress wave in the specimen continuously propagates in the matrix in the shape of a hemisphere. The brighter the graph is, the greater the stress value is. As can be seen from Fig. 3, with the continuous propagation of stress waves, the interface crack gradually expands along the direction of fiber depth from the twin fiber embedding end (the end of the steel fiber exposed to the matrix). In general, the loading peak and loading rate have significant effects on the crack growth and failure mode of the specimen interface. When the loading peak and the loading rate are small (Peak 2, Rate 5), the load value generated by the stress wave is small, which is not enough to achieve the strength required when the interface unit is completely destroyed, the interface crack propagation is slow, the interface debonding area and the specimen amount of damage is small, the failure mode of the specimen is that the fiber is not pulled out, and the specimen still has a certain bearing capacity. With the increase of loading peak and loading rate (Peak 4, Rate 2), the amount of element damage in the matrix increases, and the interface of the twin fiber is basically debonded. The macroscopic transverse main crack of the matrix between the fiber and fiber is pulled out and destroyed.When the loading peak and the loading rate are higher (Peak 6, Rate 1), the energy released during the failure of the specimen unit is higher, the interface crack propagation speed is accelerated, the interface debonding area and the damage amount of the base unit are also significantly increased, and the interface is completely debonded, the twin fiber is pulled out.

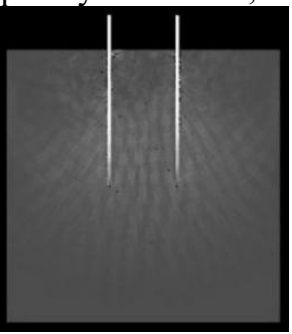

$\mathrm{t}=10 \mu \mathrm{s}$

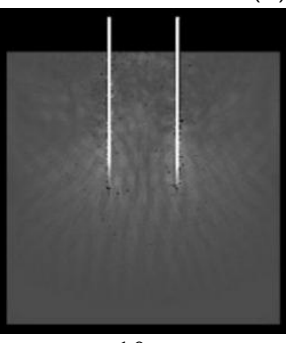

$\mathrm{t}=10 \mu \mathrm{s}$

(b) Peak 4

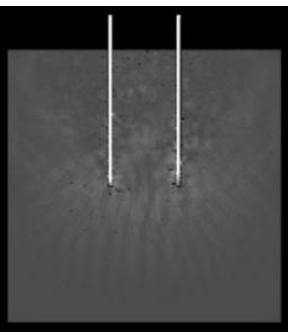

$\mathrm{t}=10 \mu \mathrm{s}$

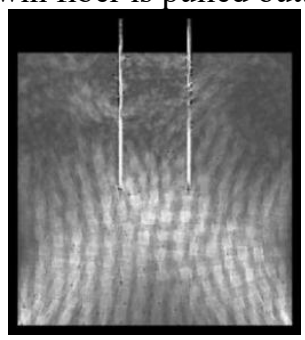

$\mathrm{t}=20 \mu \mathrm{s}$

(a) Peak 2
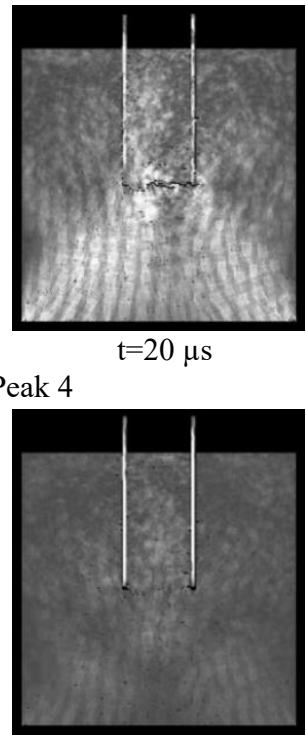

$\mathrm{t}=20 \mu \mathrm{s}$ (c) Peak 6 


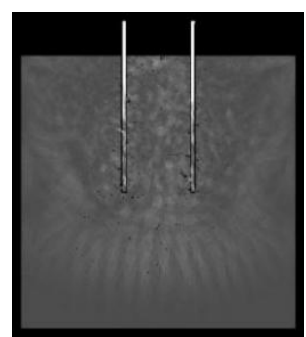
$\mathrm{t}=10 \mu \mathrm{s}$

(d) Rate 1

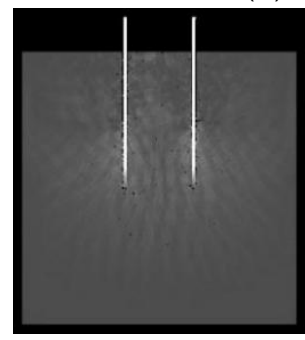

$\mathrm{t}=10 \mu \mathrm{s}$ (e) Rate 2

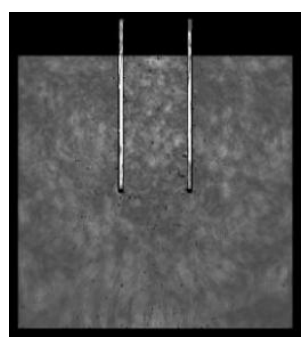

$\mathrm{t}=20 \mu \mathrm{s}$

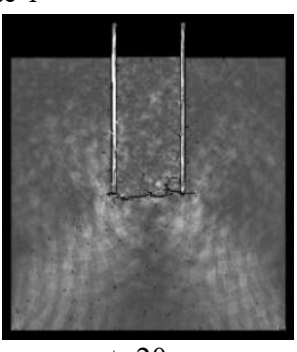

$\mathrm{t}=20 \mu \mathrm{s}$

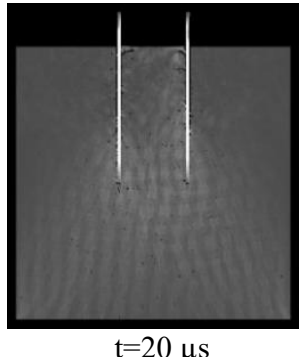

f) Rate 5

Fig3. Failure process of twin fibers pullout specime

\subsection{Acoustic emission}

Acoustic emission is the phenomenon that brittle materials such as concrete and rock are micro-ruptured under stress, strain energy released in the form of elastic waves[1415](Acoustic Emission,AE). In this study, based on the two basic assumptions that the acoustic emission number is proportional to the element damage and the acoustic emission energy is proportional to the element damage strain energy release [16], the relationship between the acoustic emission number and acoustic emission energy and the evolution of concrete damage is established.The acoustic emission counts of the specimens numbered Peak 2, Peak 6, and Rate 1, Rate 5 shown in Fig 4. It can be seen that when the loading peak value is low, the interface of the drawn specimen is not completely debonded, the damage amount of the base unit is small, and the overall acoustic emission count generated by the specimen is low from Fig. 4 . With the increase of stress wave loading peak, the debonding failure of the interface element is complete, the damage of the matrix element caused by the load increases, the number of acoustic emissions produced by the specimen is relatively dense and the value is generally large.

It can be seen that the peak of the acoustic emission of the drawing specimen is delayed as the loading rate decreases. Due to the high loading rate, the stress wave reaches the peak load in a short time, which shows that the number of damaged elements rises sharply when the specimen is damaged. When the loading rate is slow, the peaks of the acoustic emission of the specimens all appear at the end of loading, and in the early period of loading, the number of acoustic emissions is small and relatively flat.

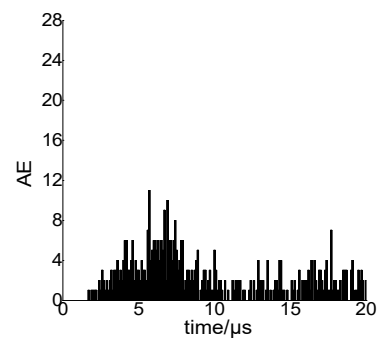

(a) Peak 2

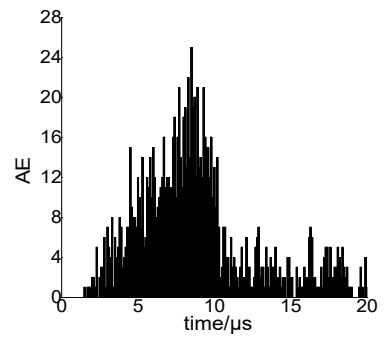

(b) Peak 6

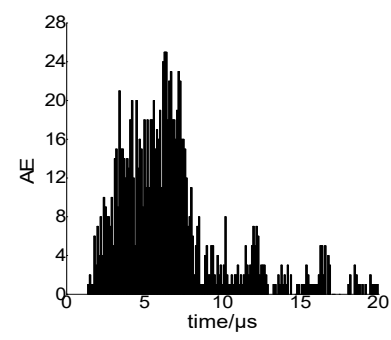

(c) Rate 1

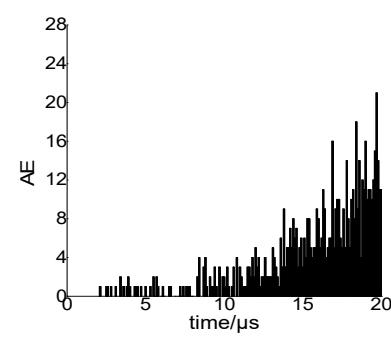

(d) Rate 5
Fig4. AE of twin fibers pullout specimens

for the acoustic emission counts of the drawn test pieces, as shown in Table 2 and Table 3, the unit crack time, peak acoustic emission time and peak acoustic emission peak of the test piece under different loading peaks and loading rates. Table 2 shows that when the loading peak is large, the cracking time of the unit is slightly earlier, but it can be basically ignored. In addition, with the increase of the loading peak, the peak time of the acoustic emission is delayed, but the number of peaks of the acoustic emission continues to increase, that is, the peak number of the acoustic emission is the maximum when the peak value of the loading test is Peak 6.Table 3, the faster the stress wave rise time, the smaller the loading rate, and the significantly higher crack initiation time and acoustic emission peak time, indicating that the reduction in loading rate can effectively delay the initial failure of the unit and the time when the acoustic emission peak appears. In addition, the number of peaks of acoustic emission basically does not change much at different loading rates, indicating that the loading rate has little effect on the peaks of acoustic emission in this study.

Table2. Elements damage initiation time and AE peak of varied loading peak

\begin{tabular}{ccccc}
\hline Numbering & $\begin{array}{c}\text { loading peaks } \\
\text { /MPa }\end{array}$ & \multicolumn{2}{c}{ Unitinitial cracking time/ $\mu$ s Time of AE peak $/ \mu \mathrm{s}$} & AE peak \\
\hline Peak 1 & 30 & 1.7 & 3.7 & 7 \\
Peak 2 & 35 & 1.7 & 5.7 & 11 \\
Peak 3 & 40 & 1.6 & 7.3 & 17 \\
Peak 4 & 45 & 1.6 & 6.8 & 21 \\
Peak 5 & 50 & 1.6 & 9.4 & 23 \\
Peak 6 & 55 & 1.5 & 8.5 & 25 \\
\hline
\end{tabular}


Acoustic emission results are shown in Fig 5、6. With the increase of loading peaks and loading rates, the cumulative energy of acoustic emission and the cumulative number of acoustic emissions of the specimen increase, indicating peak stress waves and the greater the loading rate, the more the interface debonding area and the base unit damage, the more energy is released when the specimen is damaged by loading, and the specimen damage unit increases. As shown in Fig. 5 (b) and Fig. 6 (b), when the loading peak and the loading rate are maximum, the curve of the cumulative number of acoustic emissions rises more slowly in the later stage of loading. Because the loading peak and the loading rate are relatively large, the interface of the drawn specimen has been completely debonded and destroyed, and subsequent stress waves cannot continue to be transmitted into the matrix.Gokoz ${ }^{[17]}$, Banthia et al. ${ }^{[18,19]}$ carried out pull-out tests for various types of fibers at different loading rates. The results of the study show that the increase in loading rate increases the energy dissipation capability of the material specimen. It is consistent with the results of this study that the cumulative energy of acoustic emission increases with increasing loading rate.

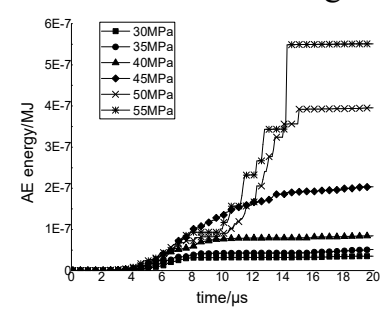

(a) Acoustic emission cumulative energy curve Fig5. AE of specimens of varied loading peak

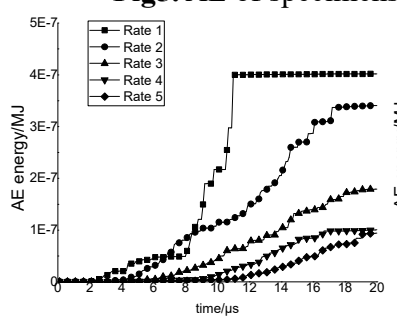

(a) Acoustic emission cumulative energy curve

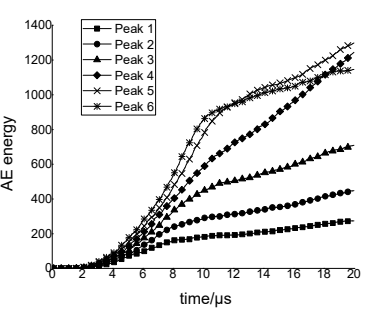

(b) Acoustic emission cumulative number curve

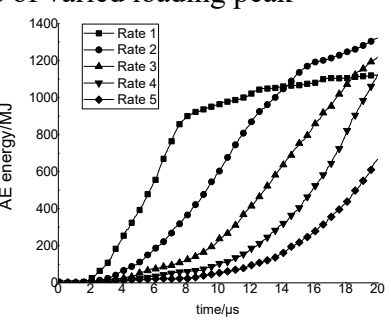

(b) Acoustic emission cumulative number curve
Fig6. AE of specimens of varied loading rate

\section{Conclusion}

(1) The dynamic failure mode of twin fibers pullout of concrete matrix has obvious correlation between loading peak and loading rate. When the loading peak and loading rate are large, the twin fibers is debonded and pulled out. The loading peak and loading rate are reduced, the twin fibers are debonded, and a macroscopic main crack that penetrates the matrix between the twin wires is formed at the buried end. When the loading peak and the loading rate are further reduced, the fiber is not completely debonded, and the test piece still have a certain bearing capacity.

(2) With the increase of the loading peak and the loading rate, the energy released when the specimen is damaged by the load increases, the interface crack growth rate of the specimen increases, the number of unit failures increases, and the specimen is seriously damaged.

(3) The loading rate affects the unit cracking time of the drawn specimen. The peak of the acoustic emission number of the test piece increases with the increase of the loading peak.

\section{Acknowledgment}

This research work is financially supported by the National Natural Science Foundation of China, Grant No. 51678170 and 51878190.

\section{References}

1. Q Wu,M Li, Y Gu. Composites Part A: Compos Part A: Appl Sci Manufac.56,143-149.(2014)

2. Kim, J K., Mai, Y W. Elsevier, (1998)

3. Jiang Y P, Yue ZF, Wan JS.J Comput Mech.20,743748.(2003)

4. Ning JG, Shang L, Sun YX. Adva Mech. 36, 389-405.(2006)

5. Kim D J, El-Tawil S, Naaman A E. AC MATERJ.105,576-584.(2008)

6. Abu-Lebdeh T, Hamoush S, Zorning B. AM. J. Eng. Appl. Sci.3,(2010)

7. Zhu DJ, Li XY, Shi CJ. J. Hunan. Univ (Natural Science Edition).(2018)

8. $\mathrm{Xu} \mathrm{M}$, Hallinan $\mathrm{B}$, Wille $\mathrm{K}$. Cement Concrete Composites.70,98-109(2016)

9. Li LJ, Zhang HZ, Liu F. New Buil.Mater10,1-5 (2004)

10. Zheng XY,Wu SX.J.Civ.Eng.39, (2006)42-46.

11. Zhang WP, Luo DY, Chen H. China J.Highw.Trans.27,58-64(2014)

12. Tang CN, Zhu WC.Beijing: Sci. Press. (2003).

13. Chen PR, Zhang YF, Li G.J.Sun Yat-Sen Univ.(Natural Science Edition).52,68-80 (2013)

14. Wang LL. Beijing: Nat.Def. Ind. Press.(2005).

15. Wan GX, Wang QS, Li XB.Exper.Mech. 27,727733(2012)

16. Tang CA, Xu XH.J.Seismo.Res.13, 203- 213(1990)

17. Gokoz UN, Naanman AE. Intern.J.Cement Composites.Lightweight Concrete.3,187-202.(1981)

18. Banthia N, Trottier JF.Cement Concrete Research.21,158-168(1991)

19. Bindiganavile V, Banthia N. Canadian J.Civ. Eng.32,924-933(2005) 